\title{
Synthesis, Characterization and Thermogravimetric Study of Some Metal Complexes of Selenazone Ligand Nanoparticles Analogue of Dithizone
}

\author{
Zuhair Ali Abdulnabi ${ }^{{ }^{*}}$, Faris Abdulridhah Jassim Al-doghachi ${ }^{2}$, and Hassan Thamir Abdulsahib ${ }^{2}$ \\ ${ }^{1}$ Department of Marine Chemistry, Marine Science Center, University of Basrah, 61004, Basrah, Iraq \\ ${ }^{2}$ Department of Chemistry, Faculty of Science, University of Basrah, 61004, Basrah, Iraq
}

${ }^{*}$ Corresponding author:

email:zuhir38@yahoo.com

Received: May 8, 2021

Accepted: June 28, 2021

DOI: $10.22146 /$ ijc.65763

\begin{abstract}
A new method for preparing 1,5-diphenylselenocarbazone (selenazone) nanoparticles and their complexes with $\mathrm{Pb}^{2+}, \mathrm{Cd}^{2+}, \mathrm{Co}^{2+}$ and $\mathrm{Ni}^{2+}$ has been performed using hot methanol solvent. The ligand and its complexes were characterized using FT$I R, U V$-Vis, ${ }^{1} \mathrm{H}-\mathrm{NMR},{ }^{13} \mathrm{C}-\mathrm{NMR}, \mathrm{X}$-ray powder diffraction (XRD), EI-mass spectrometry, scanning electron microscopy (SEM), HG and flame-atomic absorption spectrophotometer, thermal analysis (TG/DTA), and molar conductance measurements. The molar conductance measurements in all complexes were recorded low values in DMSO, indicating that all the metal complexes were non-electrolytes except the nickel complex that possessed an electrolytic nature. Kinetic and thermodynamic parameters of complexes $(A, E, \Delta H, \Delta S$, and $\Delta G)$ have been computed using three kinetic models of Coast-Redfern, Broido, and Horowitz-Metzger, that illustrated the decomposition reactions in all steps were nonspontaneous. Thermogravimetric analyses (TG/DTA) were consistent with the atomic spectroscopy data proving that the geometry shape of all the complexes was octahedral.
\end{abstract}

Keywords: selenazone nanoparticle; thermal analyses; kinetic models

\section{- INTRODUCTION}

Organoselenium compounds are defined as chemical compounds that contain both carbon and selenium atoms in their structure [1]. Wöhler and Siemens first introduced these compounds in 1847 with the synthesis of ethyl selenol [2]. Under mild conditions, organoselenium compounds can serve as valuable intermediates in synthesizing some organic compounds (e.g., the synthesis of alkyl selenoxide from alkyl selenides using oxidant agents) [3]. In the last few decades, the organic compounds of selenium were appeared to have a high activity as useful intermediates in organic compound syntheses. The high activity of these compounds can be attributed to the presence of selenium in their structure, and it also involves in several organic reactions by three routes as an electrophile, nucleophile, and a radical form [3-4]. Selenoketon compounds belong to the organoselenium compounds and are defined as chemical compounds with a double bond between carbon and selenium atoms. Generally, these compounds are relatively stable than the other species of selenium compounds with a high reactivity that helps their participation in unique reactions [2-3]. Moreover, organoselenium compounds have greater bioavailability when compared with inorganic selenium compounds and are less toxic [5-6]. The selenazone complexes as mercury bis(1,5-diphenylselenocarbazonate), chloro mercury bis(1,5-diphenylselenocarbazonate), and zinc bis (1,5-diphenylselenocarbazonate) were prepared by Coleman et al. [7]. Good results were obtained for extracting some cations from their aqueous solution by utilizing the selenazone [8]. The current study aims to synthesize selenazone ligand by a new method via replacing the sulfur atom in dithizone compound with selenium and prepare some of their complexes with divalent ions. Furthermore, the thermogravimetric analysis is conducted for all complexes. 


\section{- EXPERIMENTAL SECTION}

\section{Materials}

Dithizone, and sodium carbonate were supplied by Analar. Selenium powder and methyl iodide were obtained from Merck. Sodium borohydride was supplied from Riedel-de Haën AG Seelze-Hannover (RDH). Absolute ethanol was supplied by J.T. Baker. Methanol and dimethylsulfoxide were obtained from Himedia. Hydrochloric acid and nitric acid were supplied from GCC. Lead nitrate $\mathrm{Pb}\left(\mathrm{NO}_{3}\right)_{2}$, cadmium nitrate $\mathrm{Cd}\left(\mathrm{NO}_{3}\right)_{2} \cdot 4 \mathrm{H}_{2} \mathrm{O}$, cobalt nitrate $\mathrm{Co}\left(\mathrm{NO}_{3}\right)_{2} \cdot 6 \mathrm{H}_{2} \mathrm{O}$ and nickel chloride $\mathrm{NiCl}_{2} \cdot 6 \mathrm{H}_{2} \mathrm{O}$ were supplied by $\mathrm{BDH}$.

\section{Instrumentation}

Several techniques were used for characterizing selenazone ligand and their complexes. The melting points of the complexes have been recorded on a Fisher Johns melting point apparatus. FT-IR spectra of selenazone ligand and their complexes were measured in the region of $4000-400 \mathrm{~cm}^{-1}$ in $\mathrm{KBr}$ disk by utilizing Shimadzu FT-IR 8400 S spectrophotometer. Mass spectrometry was used to scan selenazone ligand by EI technique, 5973 Agilent technology (HP). ${ }^{1} \mathrm{H}$ and ${ }^{13} \mathrm{C}-$ NMR spectra were measured on a Bruker DRX $(500 \mathrm{MHz}$ and $100 \mathrm{MHz}$ respectively) using $\mathrm{CD}_{3} \mathrm{OD}$ and DMSO-d6. UV-Vis spectra for ligand and nickel complexes were recorded on a Shimadzu, 1800 UV-Vis spectrophotometer. $\mathrm{X}$-ray powder diffraction spectroscopy was recorded for selenazone ligand by utilizing a $\mathrm{Ka}-\mathrm{Cu}$ source at a frequency of $1.54 \AA$ (model PW 1730, Philips). The morphology of selenazone ligand was examined by scanning electron microscopy (SEM) using Zeiss microscopy at $10.00 \mathrm{kV}$. The metal content in selenazone ligand and their complexes have been determined with a Shimadzu, AA7000 atomic absorption spectrophotometer.
The molar conductance of the selenazone complexes in hot DMSO at $75^{\circ} \mathrm{C}\left(10^{-3} \mathrm{M}\right)$ was measured using WTW 3110 Condi Set1 apparatus. Finally, thermogravimetric analyses (TG/DTA) have been executed in a dynamic nitrogen atmosphere $(20 \mathrm{~mL} / \mathrm{min})$ with a heating rate at $10^{\circ} \mathrm{C} / \mathrm{min}$ by utilizing STD-Q600 thermal analyzer.

\section{Procedure}

\section{Synthesis of selenazone ligand (Z)}

1,5-diphenylthiocarbazone $(4.10 \mathrm{~g}, 16 \mathrm{mmol})$ has been dissolved in $50 \mathrm{~mL}$ absolute ethanol followed by ( $2.84 \mathrm{~g}, 20 \mathrm{mmol})$ methyl iodide. The reaction mixture was stirred for $15 \mathrm{~min}$ at room temperature and left under reflux for $1 \mathrm{~h}$ (Solution A) [9].

For the preparation of solution $\mathrm{B}$, sodium carbonate $(1.06 \mathrm{~g}, 10 \mathrm{mmol})$ was dissolved in $20 \mathrm{~mL}$ of warm deionized water and then transferred into the round bottom flask of three necks $(100 \mathrm{~mL})$ containing $1.97 \mathrm{~g}(25 \mathrm{mmol})$ of selenium powder and $1.13 \mathrm{~g}$ (30 mmol) of sodium borohydride. The mixture was then stirred at $100{ }^{\circ} \mathrm{C}$ for a short time under an inert atmosphere of argon gas. As a result, the color of the solution was changed from black to colorless. Consequently, the ethanolic solution (solution A) was added to it. The mixture was then left at room temperature and continuously stirred under inert gas of argon for $3 \mathrm{~h}$. The resulting blackish-brown precipitated solid was filtered and washed several times by absolute ethanol and deionized water. Then it was recrystallized by methanol:water (1:5). Finally, the precipitate was dried and showed some physical properties such as blackish brown color, m.p: $119-120^{\circ} \mathrm{C}$, and a yield of $65 \%$. These results obtained are consistent approximately with previous studies [7-8]. The synthesis of selenazone $(Z)$ has been carried out following reaction Scheme 1.

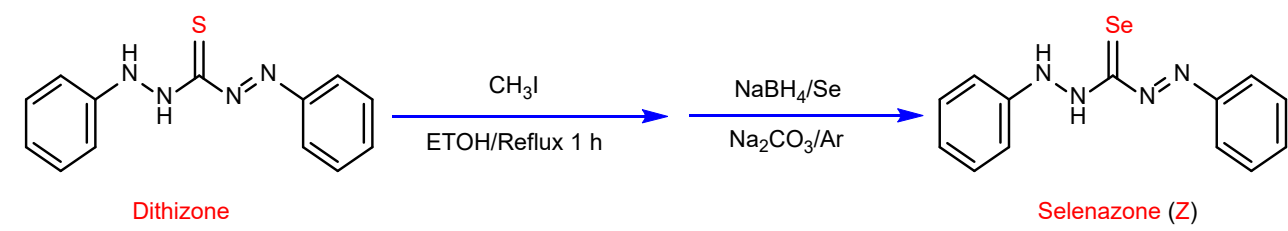

Scheme 1. Preparation of selenazone ligand (Z) 


\section{Synthesis of the transition metal complexes with selenazone ligand}

$\mathrm{ZPb}$ complex: selenazone ligand $(0.606 \mathrm{~g}, 2 \mathrm{mmol})$ was dissolved in $50 \mathrm{~mL}$ of warm methanol, and then $(0.311 \mathrm{~g}, 1 \mathrm{mmol})$ of lead nitrate dissolved in $50 \mathrm{~mL}$ of methanol was added to it. The mixture was stirred and left under reflux for $3 \mathrm{~h}$. Upon forming the blackish gray precipitate, the precipitate was filtered and washed with warm methanol several times. The obtained precipitate was then dried in the oven at $70{ }^{\circ} \mathrm{C}$ and displayed some physical properties: blackish gray color, m.p: $>300$, and a yield of $35 \%$.

ZCd complex: (0.606 g, $2 \mathrm{mmol})$ of selenazone ligand $(\mathrm{Z})$ was dissolved in $50 \mathrm{~mL}$ of warm methanol and then added to $(0.308 \mathrm{~g}, 1 \mathrm{mmol})$ of $\mathrm{Cd}\left(\mathrm{NO}_{3}\right)_{2} \cdot 4 \mathrm{H}_{2} \mathrm{O}$ in $50 \mathrm{~mL}$ of methanol. The solution was mixed with continuous stirring and left under reflux for $6 \mathrm{~h}$. A dark brown precipitate was formed. The formed precipitate was filtered and washed with warm methanol several times and was dried at $70{ }^{\circ} \mathrm{C}$ in the oven. The precipitate showed dark brown color, m.p: > 300, and a yield of 30\%.

$\mathrm{ZNi}$ complex: The nickel complex was prepared in a similar procedure to the lead complex by mixing $50 \mathrm{~mL}$ warm methanolic solution $(0.237 \mathrm{~g}, 1 \mathrm{mmol})$ of $\mathrm{NiCl}_{2} \cdot 6 \mathrm{H}_{2} \mathrm{O}$ with $50 \mathrm{~mL}$ methanolic solution of prepared ligand $(\mathrm{Z})$ $(0.606 \mathrm{~g}, 2 \mathrm{mmol})$. The mixture was left under reflux for $3 \mathrm{~h}$ with continuous stirring and was left overnight at room temperature. The mixture solution was filtered, dried, and washed with diethyl ether several times. The precipitate has a brown color, m.p: $>300$, and a yield of $75 \%$.

ZCo complex: $50 \mathrm{~mL}$ of methanolic solution of ligand $(Z)$ containing $(0.606 \mathrm{~g}, 2 \mathrm{mmol})$ was mixed with $30 \mathrm{~mL}$ of methanolic solution of $\mathrm{Co}\left(\mathrm{NO}_{3}\right)_{2} \cdot 6 \mathrm{H}_{2} \mathrm{O}$. The color of the resulted mixture changed immediately to reddish black under refluxing for $4 \mathrm{~h}$ with continuous stirring. The mixture was filtered and washed with hot methanol several times, and the precipitate was collected and revealed some physical properties like brown color, m.p: $>300$, and a yield of $30 \%$.

\section{- RESULTS AND DISCUSSION}

The current work focuses on synthesizing selenazone ligand derived from dithizone and preparing their complexes with metals ion such as lead, cadmium, nickel, and cobalt in a hot methanolic solution. The selenazone ligand has good solubility in many common organic solvents, but their complexes are insoluble in different common solvents except hot DMSO (at $75^{\circ} \mathrm{C}$ ). Therefore, many techniques were used to characterize selenazone ligands and their complexes. The results were discussed in this section.

\section{Physical Properties}

Selenazone ligand has a good solubility towards common organic solvents such as methanol, toluene, diethyl ether, dichloromethane, and xylene. However, all the $\mathrm{Pb}(\mathrm{II}), \mathrm{Cd}(\mathrm{II}), \mathrm{Ni}(\mathrm{II})$, and $\mathrm{Co}(\mathrm{II})$ complexes have some physical properties that differ from the ligand in terms of color, melting points, and solubility in which the complexes are insoluble in many common solvents except hot DMSO (at $75{ }^{\circ} \mathrm{C}$ ). The results of physical properties for preparing compounds are listed in Table 1. The values obtained from the experimental data were consistent with the theoretical values used to determine selenium in selenazone ligand by utilizing the hydride generation methods that confirm the suggested structural formula of ligand. Additionally, the percentage of metals obtained from flame-atomic absorption spectrophotometer [10] in all the complexes concurred with the experimental results that indicated a 1:4 (M:L) ratio. Besides, the values of molar conductance (using hot DMSO as solvent at $75^{\circ} \mathrm{C}$ ) indicated that all the complexes possessed a non-electrolytic nature exclusive to the nickel complex and have electrolytic nature.

\section{Spectral Characterization}

Several spectral analyses can be used to prove the suggested structure formula for selenazone ligand and their complexes as follows:

\section{Mass spectra analysis}

Mass spectrometry is an important technique for diagnosing compounds in coordination chemistry by determining the molecular ion to confirm the suggested structure formula of compounds [10]. So, selenazone ligands (Z) exhibited a peak of low intensity at $\mathrm{m} / \mathrm{z} 303$ 
Table 1. The physical properties of selenazone and their complexes

\begin{tabular}{|c|c|c|c|c|c|c|c|}
\hline \multirow{2}{*}{$\begin{array}{l}\text { Symbol } \\
\text { Comp. }\end{array}$} & \multirow{2}{*}{$\begin{array}{c}\text { Molecular formula \& } \\
\text { molecular weight }\end{array}$} & \multirow{2}{*}{ Physical state } & \multirow{2}{*}{ Color } & \multirow{2}{*}{$\begin{array}{l}\text { Melting } \\
\text { point }{ }^{\circ} \mathrm{C}\end{array}$} & \multicolumn{2}{|c|}{ Metal \% } & \multirow{2}{*}{$\begin{array}{c}\Lambda \\
\mathrm{Ohm}^{-1} \mathrm{~cm}^{2} \mathrm{~mol}^{-1}\end{array}$} \\
\hline & & & & & Found & Calc'd & \\
\hline Z & $\mathrm{C}_{13} \mathrm{H}_{12} \mathrm{~N}_{4} \mathrm{Se}$ & Powder & Blackish brown & $119-120$ & 26.86 & 25.72 & \\
\hline & 303.22 & Powder & Dlackisn Drown & $119-120$ & $\mathrm{Se}$ & $\mathrm{Se}$ & - \\
\hline $\mathrm{ZPb}$ & $\begin{array}{l}\mathrm{C}_{52} \mathrm{H}_{52} \mathrm{~N}_{16} \mathrm{O}_{3} \mathrm{PbSe}_{4} \\
1472.11\end{array}$ & Powder & Blackish gray & $>300$ & $\begin{array}{c}14.21 \\
\mathrm{~Pb}\end{array}$ & $\begin{array}{c}14.07 \\
\mathrm{~Pb}\end{array}$ & 7.27 \\
\hline ZCd & $\begin{array}{l}\mathrm{C}_{52} \mathrm{H}_{52} \mathrm{CdN}_{16} \mathrm{O}_{3} \mathrm{Se}_{4} \\
1377.33\end{array}$ & Powder & Dark brown & $>300$ & $\begin{array}{r}8.25 \\
\mathrm{Cd}\end{array}$ & $\begin{array}{c}8.18 \\
\mathrm{Cd}\end{array}$ & 3.3 \\
\hline ZCo & $\begin{array}{l}\mathrm{C}_{52} \mathrm{H}_{53} \mathrm{CoN}_{16} \mathrm{O}_{3.5} \mathrm{Se}_{4} \\
1332.86\end{array}$ & Powder & Brown & $>300$ & $\begin{array}{c}4.49 \\
\text { Co }\end{array}$ & $\begin{array}{l}4.42 \\
\text { Co }\end{array}$ & 4.48 \\
\hline $\mathrm{ZNi}$ & $\begin{array}{l}\mathrm{C}_{52} \mathrm{H}_{61} \mathrm{Cl}_{2} \mathrm{~N}_{16} \mathrm{NiO}_{6.5} \mathrm{Se}_{4} \\
1459.58\end{array}$ & Powder & Brown & $>300$ & $\begin{array}{c}4.15 \\
\mathrm{Ni}\end{array}$ & $\begin{array}{c}4.02 \\
\mathrm{Ni}\end{array}$ & 80.71 \\
\hline
\end{tabular}

with relative abundance $(0.35 \%)$, attributed to the molecular ion, while the base peak was observed at $\mathrm{m} / \mathrm{z} 77$ $(100 \%)$ that correspond to $\left[\mathrm{C}_{6} \mathrm{H}_{5}\right]^{+}$. The fragment of molecular ion for selenium isotope $\left({ }^{80} \mathrm{Se}\right)$ appeared at $\mathrm{m} / \mathrm{z}$ $305(0.01 \%)$. Furthermore, a new fragment revealed at $\mathrm{m} / \mathrm{z} 606(0.05 \%)$ may be indicating to form dimers structure of selenazone ligand $(\mathrm{Z})$. The mass spectrum of selenazone is shown in Fig. 1.

\section{$X$-ray diffraction pattern}

$\mathrm{X}$-ray diffraction spectroscopy provides useful information about the crystal size and crystalline phase and assists in characterizing compounds [11]. Selenazone ligand was prepared by replacing the sulfur atom with a selenium atom. The pattern of the selenazone ligand $(\mathrm{z})$ showed several bands with positions at $2 \theta=18.9^{\circ}, 23.5^{\circ}, 26.6^{\circ}, 29.6^{\circ}, 41.4^{\circ}, 43.6^{\circ}$, $45.4^{\circ}, 51.74^{\circ}, 56.2^{\circ}, 61.7^{\circ}, 65.4^{\circ}$, and $71.7^{\circ}$, due to the existence of selenium atom in the structural formula of selenazone ligand that appropriate with the results that obtained in the previous studies [12-13]. On the other hand, the bands of sulfur atoms disappeared in the pattern of selenazone ligand that enhanced the formation

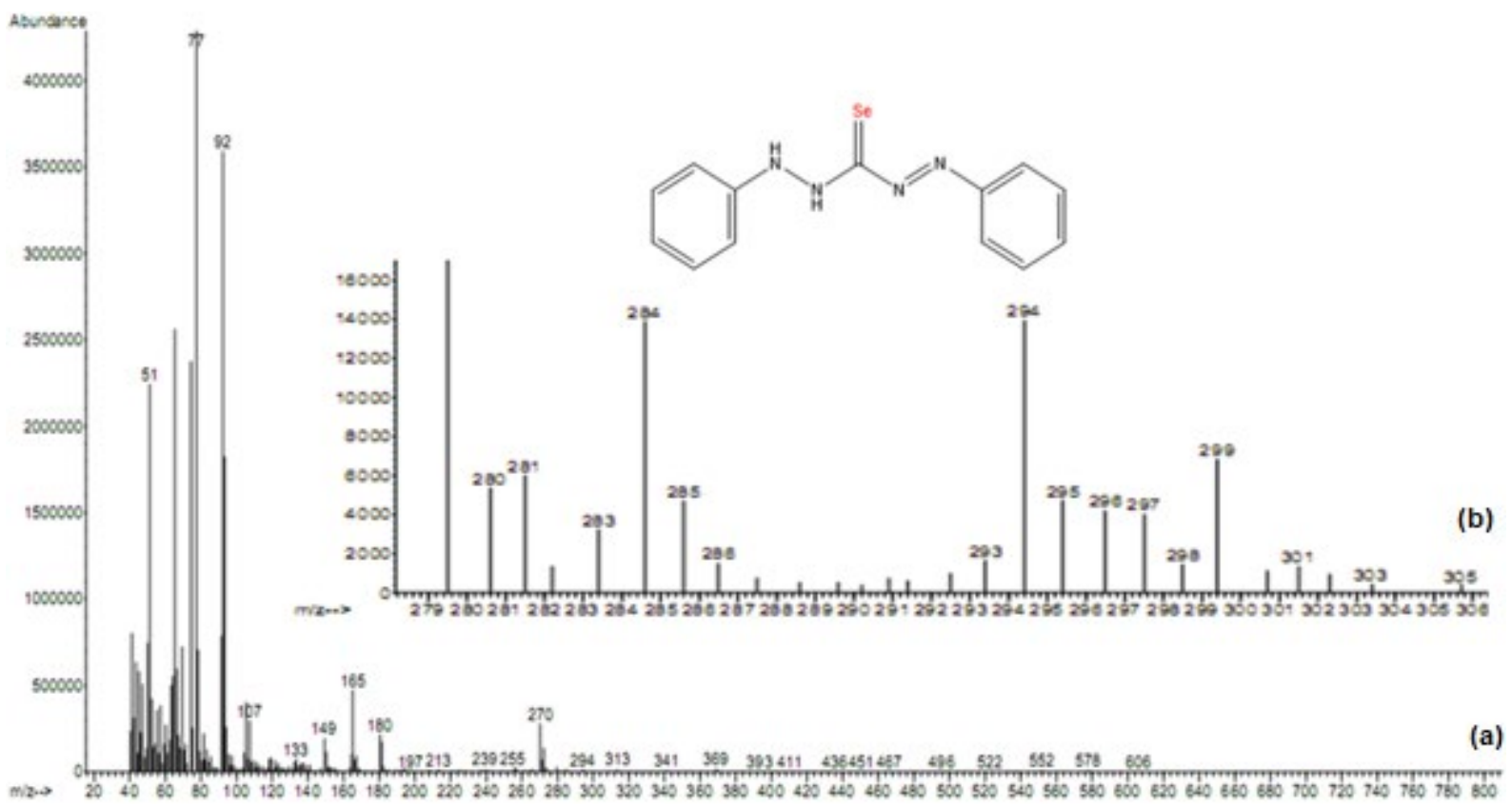

Fig 1. (a) Mass spectrum of selenazone ligand (Z) (b) The expanded mass spectrum of selenazone ligand 
of the suggested structure formula of selenazone ligand. The crystal size of selenazone (Z) was computed by Debye Scherrer's equation [11-13], proving that the average size of the crystals $(19.78 \mathrm{~nm})$ of selenazone was within the nanoparticles class. The XRD data of selenazone ligand are explained in Table 2 and Fig. 2.

\section{Scanning electron microscopy (SEM)}

The SEM technique provides good information about the topology of the compounds by yielding images through scanning the surface of the sample after coating with gold and a concentrated beam of accelerated electrons [14-15]. The SEM image (Fig. 3) was utilized to prove a selenium atom in the structure of the selenazone ligand. The results revealed that the shape of nanorods was attributed to the selenium atom. These findings were suitable with the XRD data that confirm the existence of selenium in the selenazone structure. Likewise, the SEM result was consistent with previous studies that prove the existence of selenium nanoparticles [12].

\section{FT-IR spectroscopy}

The IR spectrum of selenazone ligand $(Z)$ was measured by $\mathrm{KBr}$ disk in the region $4000-400 \mathrm{~cm}^{-1}$. The IR spectrum demonstrated a new peak at $980 \mathrm{~cm}^{-1}$ attributed to the group of $\mathrm{C}=\mathrm{Se}$ in the ligand structure [16]. Some peaks disappeared in the spectrum of selenazone ligand when compared with the dithizone spectrum, such as $\mathrm{C}=\mathrm{S}, \mathrm{C}-\mathrm{S}, \mathrm{C}=\mathrm{N}$, and $\mathrm{S}-\mathrm{H}$ groups. The data obtained from the FT-IR spectrum confirm the formation of selenazone ligand via the replacement of the selenium atom rather than the sulfur atom. Moreover, the tautomeric forms disappeared in the selenazone ligand compared to the dithizone spectrum without the $\mathrm{C}=\mathrm{N}$ group. Also, new peaks were observed, such as $\mathrm{C}-$ $\mathrm{Se}$, and $\mathrm{Se}-\mathrm{H}$, while the peak of $\mathrm{C}=\mathrm{Se}$ disappeared when comparing the IR spectra between selenazone ligand with

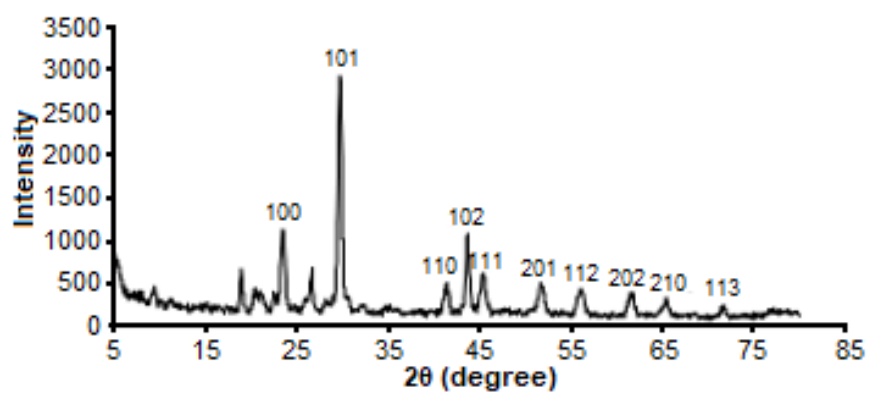

Fig 2. XRD spectrum of selenazone ligand (Z)

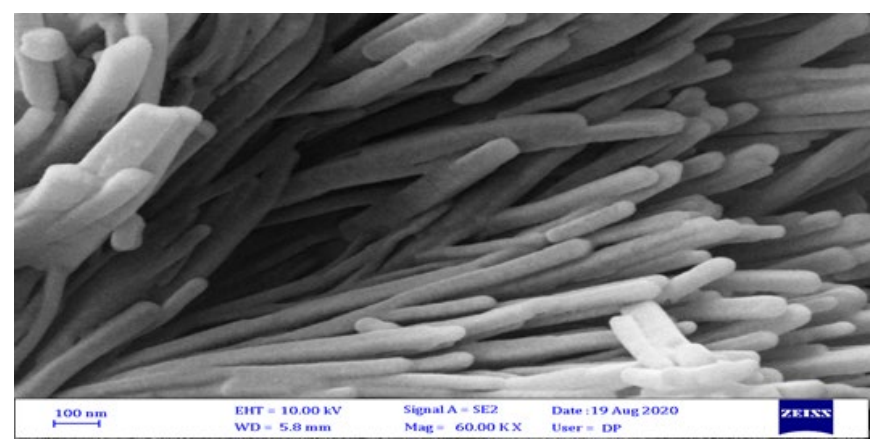

Fig 3. SEM image of selenazone ligand (Z)

Table 2. The XRD data of selenazone ligand $(\mathrm{Z})$

\begin{tabular}{crcccc}
\hline $\begin{array}{c}\text { Pos. } \\
{\left[2 \theta^{\circ}\right]}\end{array}$ & $\begin{array}{c}\text { Height } \\
{[\mathrm{cts}]}\end{array}$ & $\begin{array}{c}\text { FWHM } \\
{\left[2 \theta^{\circ}\right]}\end{array}$ & $\begin{array}{c}\text { d-spacing } \\
{[\AA]}\end{array}$ & $\begin{array}{c}\text { Rel. Int. } \\
{[\%]}\end{array}$ & $\begin{array}{c}\text { Crystal size } \\
(\mathrm{D} \mathrm{nm})\end{array}$ \\
\hline 18.9624 & 558.64 & 0.2952 & 4.68017 & 20.83 & 27.28 \\
23.5491 & 1027.11 & 0.4428 & 3.77798 & 38.29 & 18.32 \\
26.6454 & 448.61 & 0.2952 & 3.34557 & 16.72 & 27.65 \\
29.6836 & 2682.40 & 0.3936 & 3.00970 & $\mathbf{1 0 0 . 0 0}$ & $\mathbf{2 0 . 8 8}$ \\
41.4472 & 356.82 & 0.5904 & 2.17865 & 13.30 & 14.38 \\
43.6544 & 932.45 & 0.2460 & 2.07348 & 34.76 & 34.78 \\
45.4515 & 476.39 & 0.5904 & 1.99559 & 17.76 & 14.58 \\
51.7456 & 375.11 & 0.5904 & 1.76669 & 13.98 & 14.95 \\
56.2229 & 283.18 & 0.8856 & 1.63616 & 10.56 & 10.17 \\
61.7438 & 263.21 & 0.8856 & 1.50245 & 9.81 & 10.45 \\
65.4836 & 181.85 & 0.3936 & 1.42541 & 6.78 & 23.99 \\
71.7806 & 102.39 & 0.4920 & 1.31506 & 3.82 & 19.92 \\
\hline
\end{tabular}

Zuhair Ali Abdulnabi et al. 
Table 3. The results of FT-IR for selenazone ligand and their complexes

\begin{tabular}{ccccccc}
\hline Functional group $\left(\mathrm{cm}^{-1}\right)$ & Dithizone & Selenazone $(\mathrm{Z})$ & $\mathrm{ZPb}$ & $\mathrm{ZCd}$ & $\mathrm{ZCo}$ & $\mathrm{ZNi}$ \\
\hline $\mathrm{N}-\mathrm{H}$ & 3435,3400 & 3278 & 3266 & 3267 & 3280 & - \\
$\mathrm{O}-\mathrm{H}$ & - & - & 3421 & 3450 & 3433 & 3404 \\
$\mathrm{C}-\mathrm{H}$ Arom. & 3003,3091 & 3026,3047 & 3154,3131 & 3010 & 3159,3053 & 3062 \\
$\mathrm{~N}=\mathrm{N}$ & 1490 & 1494 & 1469 & 1490 & 1477 & 1485 \\
$\mathrm{C}=\mathrm{C}$ & $1597-1444$ & $1597-1408$ & $1597-1405$ & $1558-1427$ & $1600-1400$ & $1600-1400$ \\
$\mathrm{~S}-\mathrm{H}$ & 2530 & - & - & - & - & - \\
$\mathrm{C}=\mathrm{S}$ & $894,860,1062$ & - & - & - & - & - \\
$\mathrm{C}-\mathrm{S}$ & 501 & - & - & - & - & - \\
$\mathrm{Se}-\mathrm{H}$ & - & - & 2207 & 2260 & 2177 & 2308 \\
$\mathrm{C}=\mathrm{Se}$ & - & - & - & - & - & - \\
$\mathrm{C}-\mathrm{Se}$ & - & - & 1635 & 1645 & 1622 & 1633 \\
$\mathrm{C}=\mathrm{N}$ & 1627 & 1226 & 1257 & 1222 & 1247 & 1263 \\
$\mathrm{C}-\mathrm{N}$ & 1219 & - & 455 & 626 & 648 & 501 \\
$\mathrm{M}-\mathrm{N}$ & - & & & & 574 & 580 \\
\hline
\end{tabular}

their complexes. A strong band was observed at $3278 \mathrm{~cm}^{-1}$ [17-18], attributed to the amine group in the selenazone ligand. This band shifted towards a lower wavenumber in the complexes spectra about $\left(\Delta v=2-12 \mathrm{~cm}^{-1}\right)$ due to the share amine group with metal ions through the lone pair of electrons on the nitrogen atom.

Furthermore, the azo group also formed complexes by coordinating with metal ions through the lone pair of electrons on the nitrogen atom [18]. As a result, their wavenumbers in the complexes' spectra shifted to lower values $\left(\Delta v=4-25 \mathrm{~cm}^{-1}\right)$. All complexes spectra exhibited a new peak in the $3404-3450 \mathrm{~cm}^{-1}$ and $455-648 \mathrm{~cm}^{-1}$ attributed to the $\mathrm{O}-\mathrm{H}$ and $\mathrm{M}-\mathrm{N}$ bonds $[10,19]$. The IR data of compounds are listed in Table 3.

\section{UV-Vis spectroscopy}

The electronic spectra of dithizone and selenazone were recorded within 200-800 $\mathrm{nm}$ in ethanol and methanol as solvents, respectively. Dithizone showed many bands at $226,266,277,295,444$, and $593 \mathrm{~nm}$ due to $\pi-\pi^{*}$ and $n-\pi^{*}$ transitions. The bands at 444 and $593 \mathrm{~nm}$ were attributed to thiol -thione formation. These refer to the presence of tautomerism in the dithizone structure [20]. The electronic spectrum of selenazone displayed four bands at 267, 296, 413 and $535 \mathrm{~nm}$ attributed to $\pi-\pi^{*}$ and $n-\pi^{*}$ transitions with molar extinction coefficients at $8620,5810,10750,3350 \mathrm{~L} \mathrm{~mol}^{-1} \mathrm{~cm}^{-1}$ respectively. These bands confirm the formation of the selenazone ligand and the disappearance of the tautomeric forms from the selenazone ligand structure. The electronic spectrum of nickel complex showed a strong band at $261 \mathrm{~nm}(22020 \mathrm{~L}$ $\mathrm{mol}^{-1} \mathrm{~cm}^{-1}$ ) attributed to transition motions of phenyl rings. This band's wavelength was unaffected compared with the selenazone ligand $(Z)$ spectrum, indicating unshare the phenyl rings in the complex formation. The transition band that appeared in ligand spectrum at 296, 413 , and $535 \mathrm{~nm}$ are shifted in nickel complex spectrum towards a redshift and hypochromic effect at 328,420 and $549 \mathrm{~nm}$ with molar extinction coefficients at 9890 , 3070 , and $2380 \mathrm{~L} \mathrm{~mol}^{-1} \mathrm{~cm}^{-1}$ respectively. This indicates the involvement of the nitrogen atom in azo and amine groups for coordinating with nickel ion. A new band also shows at $666 \mathrm{~nm}\left(143.4 \mathrm{~L} \mathrm{~mol}^{-1} \mathrm{~cm}^{-1}\right)$ in the complex spectrum due to $\mathrm{d}$-d transition [21]. All results of electronic spectra are shown in Fig. 4.

\section{${ }^{1} \mathrm{H}$ and ${ }^{13} \mathrm{C}-\mathrm{NMR}$ spectra analysis}

The results of the ${ }^{1} \mathrm{H}-\mathrm{NMR}$ spectral of the selenazone ligand at ambient temperature in $\mathrm{CD}_{3} \mathrm{OD}$ prove the suggested structure elucidation of the selenazone ligand. The ${ }^{1} \mathrm{H}-\mathrm{NMR}$ spectrum showed two singlet signals at chemical shift $\delta=2.33,2.48 \mathrm{ppm}$ attributed to the protons of amine groups $(\mathrm{N}-\mathrm{H})$ [22]. On the other hand, multi signals appeared in the chemical shift range from 6.70 to $7.68 \mathrm{ppm}$. These correspond to ten protons attributed to the protons of 


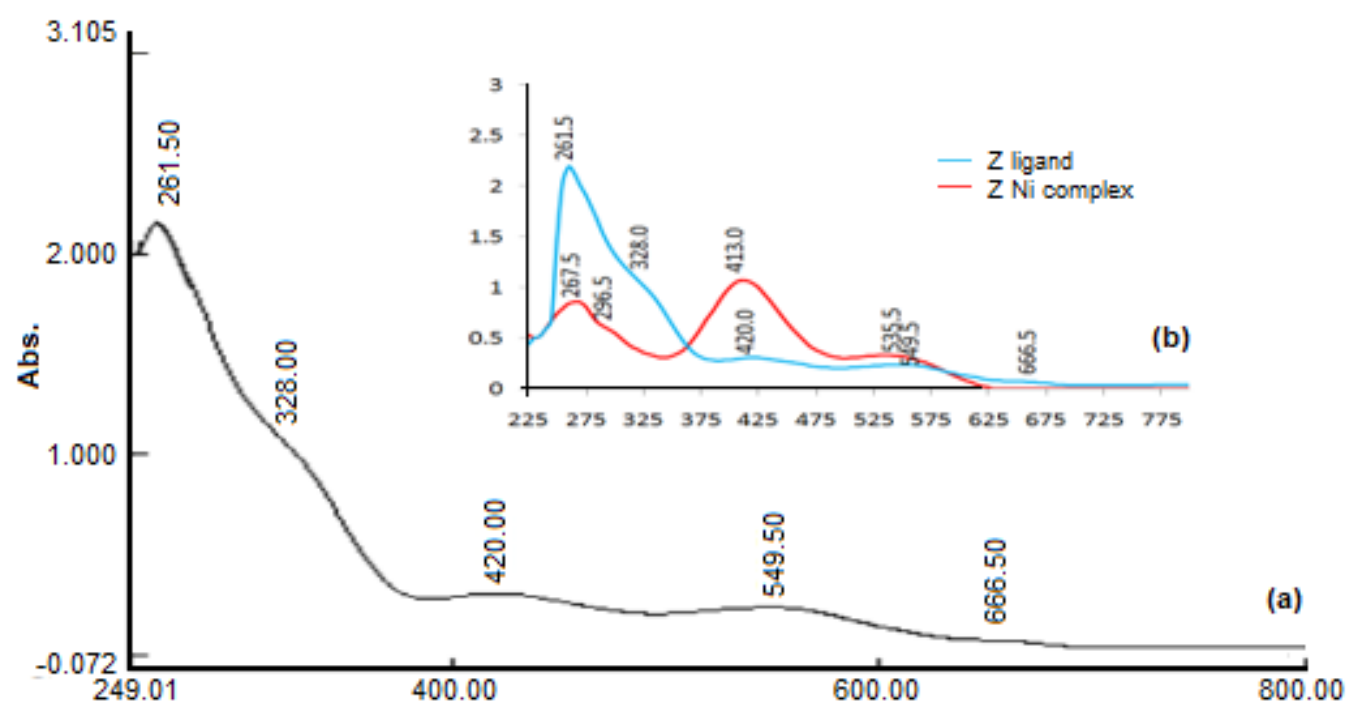

Fig 4. (a) The UV-Vis spectrum of nickel complex (b) The UV-Vis spectrum of selenazone and nickel complex

phenyl rings [10,23-24]. Nickel complex was revealed a good solubility in DMSO solvent at room temperature, while the other complexes were insoluble in all organic solvents so, the ${ }^{1} \mathrm{H}$-NMR spectrum data of nickel complex was recorded only in DMSO- $\mathrm{d}_{6}$ solvent and showed multi signals to aromatic protons at chemical shift $\delta=7.63-$ $7.79 \mathrm{ppm}$. The signal at $\delta=2.89 \mathrm{ppm}$ due to the protons of the amine groups was a little affected when compared with the selenazone ligand spectrum. This result confirms their participation in coordinating with nickel ions. The chemical shifts of all the carbon atoms for selenazone ligand and Ni complex spectra were measured and listed in Table 4.

Moreover, the numbering of all the carbon atoms was employed, as shown in Fig. 5. As a result, the ${ }^{13} \mathrm{C}-\mathrm{NMR}$ spectrum of nickel complex showed a signal at

Table 4. Chemical shifts of selenazone ligand and nickel complex in ${ }^{13} \mathrm{C}-\mathrm{NMR}$ spectra

\begin{tabular}{|c|c|c|}
\hline \multirow{2}{*}{ Carbon atoms } & \multicolumn{2}{|c|}{ Chemical shift (ppm) } \\
\hline & $\mathrm{Z}$ & $\mathrm{ZNi}$ \\
\hline $\mathrm{C}_{1}$ & - & 168.76 \\
\hline $\mathrm{C}_{2,2^{\prime}}$ & 130.28 & 130.77 \\
\hline $\mathrm{C}_{3,3^{\prime}}$ & 113 & 126.78 \\
\hline $\mathrm{C}_{4,4^{\prime}}$ & 129.86 & 134.56 \\
\hline $\mathrm{C}_{5}$ & 119 & 126.78 \\
\hline $\mathrm{C}_{6,6}$ & 114 & 126.78 \\
\hline $\mathrm{C}_{7,7^{\prime}, 7^{\prime \prime}}$ & 129.72 & 133.27 \\
\hline
\end{tabular}

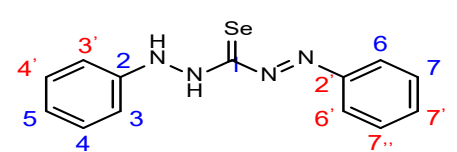

Fig 5. the numbering of carbon atoms of selenazone ligand

$\delta=168.76 \mathrm{ppm}$ attributed to the direct contact of carbon atom $\left(C_{1}\right)$ with the selenium atom. On the other hand, the carbon atom $\left(\mathrm{C}_{2,2^{\prime}}\right)$ signal in the phenyl ring directly connected with the nitrogen atom was observed at $\delta=$ 130.77 ppm. Thus, the signal was relatively affected in the spectrum of the nickel complex that confirms the sharing of the amine and azo groups in coordination towards nickel ion [24]. The results of the ${ }^{1} \mathrm{H}$ and ${ }^{13} \mathrm{C}$ NMR spectra of selenazone and nickel complex are depicted in Fig. 6 and 7.

\section{Thermal Analyses of Complexes}

Thermogravimetric analysis is a useful technique that provides more information about the configuration of the structure of organic and inorganic compounds, leading to the diagnosis of these compounds. In addition, the analysis can assist in studying important parameters such as the thermal stability of the compound, water molecules (lattice or coordinated), decomposition mechanism of compounds, and determine the quality and quantity of residual amount [24-25]. Thermal analyses such as thermogravimetric (TG) and differential 


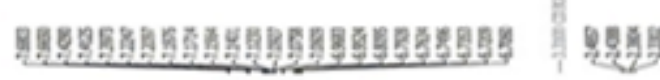

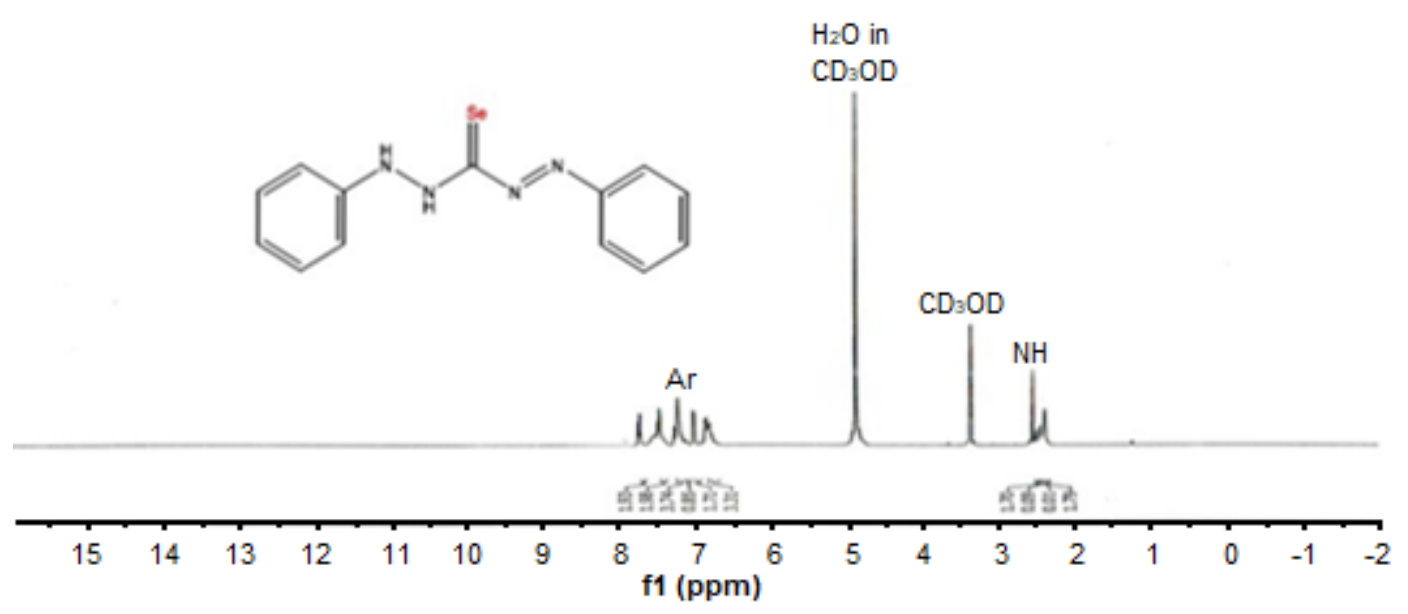

Fig 6. ${ }^{1} \mathrm{H}-\mathrm{NMR}$ of selenazone ligand $(\mathrm{Z})$

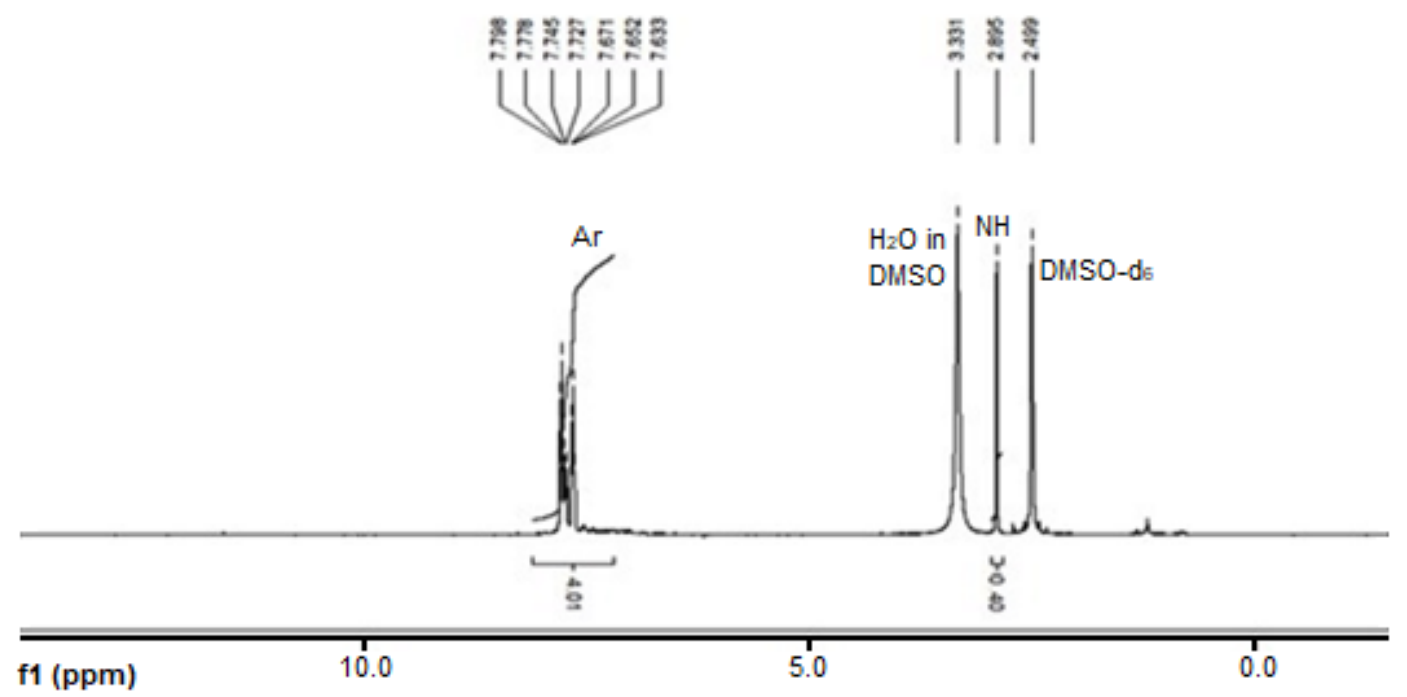

Fig 7. ${ }^{1} \mathrm{H}-\mathrm{NMR}$ of nickel complex $\mathrm{ZNi}$

thermal analyses (DTA) were recorded in the thermal range from room temperature to $1200{ }^{\circ} \mathrm{C}$ under nitrogen gas flow and heating rate of $10^{\circ} \mathrm{C} / \mathrm{min}$.

Lead complex $(\mathrm{ZPb})$ : The lead complex's thermal analysis curve (TG/DTA) showed four decomposition steps. The first is represented as two degradation steps, combined in the extent of $20-255^{\circ} \mathrm{C}\left(\mathrm{DTA}_{\max } 224^{\circ} \mathrm{C}\right)$ with a weight loss ratio of $3.28 \%$ (theoretical $3.66 \%$ ), consistent with the loss of three molecules of water (one molecule of lattice water and two molecules of coordinated water) $[10,24]$. The following steps considered a degradation of the selenazone ligand, and the residual product at $975{ }^{\circ} \mathrm{C}$ is $15.02 \%$ (theoretical 15.16\%) due to $\mathrm{PbO}$.

Cadmium complex (ZCd): Three degradation steps were revealed and showed endo-exothermic peaks indicating a change in the phases [25]. The first decomposition stage showed an endothermic peak at $102{ }^{\circ} \mathrm{C}$, referring to the loss of one molecule of lattice water in the range of $30-155^{\circ} \mathrm{C}\left(\mathrm{DTA}_{\max } 100^{\circ} \mathrm{C}\right)$ with a weight loss ratio of $1.028 \%$ (theoretical $1.3 \%$ ). The second stage also exhibited an endothermic peak at $230{ }^{\circ} \mathrm{C}$ in the DTA curve by decomposition range of $160-255{ }^{\circ} \mathrm{C}$ $\left(\mathrm{DTA}_{\max } 230^{\circ} \mathrm{C}\right)$ with a weight loss ratio of $2.031 \%$ 
(theoretical 2.64\%), attributed to the loss of two molecules of coordinated water. The final steps refer to ligand decomposition, where the remaining product at $565{ }^{\circ} \mathrm{C}$ was $11.61 \%$ (theoretical $11.93 \%$ ), attributed to cadmium oxide CdO polluted with three carbon atoms $[10,18,26-$ 27].

Cobalt complex (ZCo): The decomposition of the cobalt complex is revealed by five degradation steps. The first step was at the extent of $30-120^{\circ} \mathrm{C}\left(\mathrm{DTA}_{\max } 75^{\circ} \mathrm{C}\right)$ with a weight loss ratio of $1.86 \%$ (theoretical $2.02 \%$ ), which was appropriate with the loss of 1.5 molecules of lattice water. Additionally, two molecules of coordinated water with cobalt ion were lost in the range of $125-250^{\circ} \mathrm{C}$ $\left(\mathrm{DTA}_{\max } 216^{\circ} \mathrm{C}\right.$ ) that corresponding with a ratio of $2.71 \%$ (theoretical 2.75\%). Finally, the molecules of selenazone ligand were unstable and destroyed with the increasing temperature. Hence, the remaining amount at $980{ }^{\circ} \mathrm{C}$ was identified as cobalt oxide with a constant weight ratio of $5.75 \%$ (theoretical 5.62\%).

Nickel complex (ZNi): Five degradation steps for completing the nickel complex. The first step begins in the range of $30-110^{\circ} \mathrm{C}\left(\mathrm{DTA}_{\max } 90^{\circ} \mathrm{C}\right)$ with a weight loss ratio of $5.50 \%$ (theoretical 5.54\%), consistent with the loss of 4.5 molecules of lattice water. The second step was recorded in the range $115-190{ }^{\circ} \mathrm{C}\left(\mathrm{DTA}_{\max } 175^{\circ} \mathrm{C}\right)$ that attributed to the loss of two molecules of coordinated water and one molecule of $\mathrm{HCl}$ this convenient with a lost weight of 5.49\% (theoretical 5.25\%). Finally, the residual amount after the last step at $690{ }^{\circ} \mathrm{C}$ was suitable with 4.99\% (theoretical 5.12\%) due to nickel oxide NiO. Accordingly, the spectroscopic and thermal results confirmed the octahedral geometry structure in all complexes as proposed in Fig. 8.

\section{Calculation of Kinetic and Thermodynamic Parameters}

The thermal dehydration and degradation of complexes were studied kinetically utilizing three kinetic models such as Coast-Redfern, Broido, and HorowitzMetzger [26-28]. The thermodynamic activation parameters of degradation process and dehydration of complexes such as reaction orders (n), activation energy (E), pre-exponential factors (A), enthalpy of activation $(\Delta \mathrm{H})$, the entropy of activation $(\Delta \mathrm{S})$, and Gibbs free energy change of the degradation $(\Delta \mathrm{G})$ were computed graphically from TG/DTA data by employing three kinetic models and comparing them. The kinetic models relations are explained in the following forms:

$$
\begin{aligned}
\log \left[\frac{\log \frac{\mathrm{W}_{\mathrm{f}}}{\mathrm{W}_{\mathrm{f}}-\mathrm{W}_{\mathrm{t}}}}{\mathrm{T}^{2}}\right] \\
\quad=\log \left[\frac{\mathrm{AR}}{\theta \mathrm{E}}\left(1-\frac{2 \mathrm{RT}}{\mathrm{E}}\right)\right]-\frac{\mathrm{E}}{2.303 \mathrm{RT}} \quad \text { Coast-Redfern }
\end{aligned}
$$

$\ln \ln \left[\frac{1}{\mathrm{Y}}\right]=\frac{-\mathrm{E}}{\mathrm{RT}}+$ Constant $\quad$ Broido

$\ln \ln \left[\frac{\mathrm{W}_{\mathrm{o}}}{\mathrm{W}_{\mathrm{t}}}\right]=\frac{\theta \mathrm{E}}{\mathrm{RT}_{\mathrm{s}}^{2}} \quad$ Horowitz-Metzger

where $\mathrm{W}_{\mathrm{f}}, \mathrm{W}_{\mathrm{t}}, \mathrm{W}_{\mathrm{o}}$ are weight loss at the final step, weight loss at temperature $\left({ }^{\circ} \mathrm{C}\right)$ and initial weight, respectively. The terms E, R, A, and $\theta$ represent the activation energy, gas constant, pre-exponential factor, and heating rate $\left(10^{\circ} \mathrm{C} \mathrm{min}^{-1}\right)$, respectively. Moreover, the terms $\mathrm{Y}$ and $\theta$

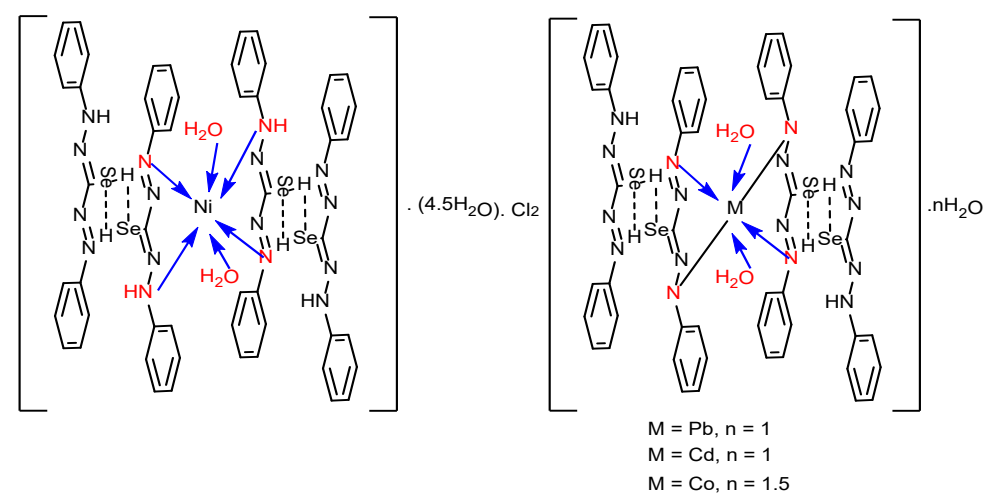

Fig 8. Suggested structure of selenazone complexes 
Table 5. Thermodynamic parameters using Coats-Redfern relation

\begin{tabular}{clcccccc}
\hline \multirow{2}{*}{ Complex } & Step & $\begin{array}{c}\mathrm{A} \\
\left(\mathrm{S}^{-1}\right)\end{array}$ & $\begin{array}{c}\mathrm{E} \\
\left(\mathrm{KJ} \mathrm{mol}^{-1}\right)\end{array}$ & $\begin{array}{c}\Delta \mathrm{H} \\
\left(\mathrm{KJ} \mathrm{mol}^{-1}\right)\end{array}$ & $\begin{array}{c}\Delta \mathrm{S} \\
\left(\mathrm{KJ} \mathrm{mol}^{-1} \mathrm{~K}^{-1}\right)\end{array}$ & $\begin{array}{c}\Delta \mathrm{G} \\
\left(\mathrm{KJ} \mathrm{mol}^{-1}\right)\end{array}$ & $\mathrm{r}$ \\
\hline \multirow{3}{*}{$\mathrm{ZPb}$} & $1^{\text {st }}$ & $23.66 \times 10^{-3}$ & 13.567 & 9.634 & -0.279 & 142.014 & 0.960 \\
& $2^{\text {nd }}$ & $1.47 \times 10^{5}$ & 108.724 & 102.755 & -0.153 & 212.782 & 0.989 \\
& $3^{\text {rd }}$ & $1.04 \times 10^{14}$ & 267.774 & 261.015 & 0.015 & 248.726 & 0.957 \\
& $4^{\text {th }}$ & $1.22 \times 10^{2}$ & 110.611 & 101.815 & -0.215 & 329.787 & 0.969 \\
\hline \multirow{3}{*}{$\mathrm{ZCd}$} & $1^{\text {st }}$ & 2.8307 & 23.837 & 20.736 & -0.238 & 109.555 & 0.926 \\
& $2^{\text {nd }}$ & $1.387 \times 10^{7}$ & 90.929 & 86.831 & -0.112 & 142.227 & 0.985 \\
& $3^{\text {rd }}$ & $4.735 \times 10^{3}$ & 93.405 & 87.019 & -0.182 & 227.115 & 0.976 \\
\hline \multirow{3}{*}{$\mathrm{ZCo}$} & $1^{\text {st }}$ & 20.2979 & 27.425 & 24.532 & -0.221 & 101.497 & 0.987 \\
& $2^{\text {nd }}$ & $1.025 \times 10^{3}$ & 53.046 & 48.988 & -0.191 & 142.376 & 0.987 \\
& $3^{\text {rd }}$ & $2.11 \times 10^{2}$ & 643.365 & 636.938 & -0.208 & 797.975 & 0.905 \\
& $4^{\text {th }}$ & $1.67 \times 10^{15}$ & 299.292 & 291.868 & 0.0373 & 258.478 & 0.993 \\
& $5^{\text {th }}$ & $2.057 \times 10^{2}$ & 122.573 & 112.363 & -0.212 & 373.182 & 0.894 \\
\hline \multirow{2}{*}{$\mathrm{ZNi}$} & $1^{\text {st }}$ & $2.524 \times 10^{5}$ & 52.968 & 50.0338 & -0.142 & 100.475 & 0.964 \\
& $2^{\text {nd }}$ & $1.21 \times 10^{8}$ & 89.112 & 85.388 & -0.093 & 127.291 & 0.991 \\
& $3^{\text {rd }}$ & $95.21 \times 10^{-2}$ & 30.263 & 25.873 & -0.250 & 157.910 & 0.895 \\
& $4^{\text {th }}$ & $7.989 \times 10^{7}$ & 142.96 & 137.156 & -0.100 & 207.444 & 0.953 \\
& $5^{\text {th }}$ & $4.368 \times 10^{6}$ & 156.621 & 149.654 & -0.126 & 255.562 & 0.941 \\
\hline
\end{tabular}

Table 6. Thermodynamic parameters using Broido relation

\begin{tabular}{llcrc}
\hline Complex & Step & $\begin{array}{c}\mathrm{E} \\
\left(\mathrm{KJ} \mathrm{mol}^{-1}\right)\end{array}$ & $\begin{array}{c}\Delta \mathrm{H} \\
\left(\mathrm{KJ} \mathrm{mol}^{-1}\right)\end{array}$ & $\mathrm{r}$ \\
\hline \multirow{3}{*}{$\mathrm{ZPb}$} & $1^{\text {st }}$ & 14.815 & 10.882 & 0.995 \\
& $2^{\text {nd }}$ & 104.571 & 98.602 & 0.990 \\
& $3^{\text {rd }}$ & 185.99 & 179.230 & 0.866 \\
& $4^{\text {th }}$ & 111.248 & 102.451 & 0.929 \\
\hline \multirow{3}{*}{$\mathrm{ZCd}$} & $1^{\text {st }}$ & 21.040 & 17.939 & 0.882 \\
& $2^{\text {nd }}$ & 72.597 & 68.498 & 0.935 \\
& $3^{\text {rd }}$ & 97.420 & 91.034 & 0.989 \\
\hline \multirow{4}{*}{$\mathrm{ZCo}$} & $1^{\text {st }}$ & 20.661 & 17.768 & 0.984 \\
& $2^{\text {nd }}$ & 46.216 & 42.159 & 0.973 \\
& $3^{\text {rd }}$ & 702.927 & 697.148 & 0.952 \\
& $4^{\text {th }}$ & 249.898 & 242.474 & 0.965 \\
& $5^{\text {th }}$ & 123.132 & 112.923 & 0.895 \\
\hline \multirow{3}{*}{$\mathrm{ZNi}$} & $1^{\text {st }}$ & 40.710 & 37.776 & 0.972 \\
& $2^{\text {nd }}$ & 77.978 & 74.253 & 0.975 \\
& $3^{\text {rd }}$ & 15.175 & 10.785 & 0.756 \\
& $4^{\text {th }}$ & 116.619 & 110.816 & 0.891 \\
& $5^{\text {th }}$ & 151.873 & 144.906 & 0.908 \\
\hline
\end{tabular}

in Broido and Horowitz-Metzger relations refer to $\left(\mathrm{W}_{\mathrm{t}}-\right.$ $\left.\mathrm{W}_{\infty}\right) /\left(\mathrm{W}_{\mathrm{o}}-\mathrm{W}_{\infty}\right)$ and $\mathrm{T}-\mathrm{T}_{\mathrm{s}}$, respectively [29-30]. In the current work, the degradation steps in all the complexes were consistent with the first order reaction in all the degradation steps. The correlation coefficient ( $r$ ) was calculated by utilizing the least square method through plotting the left side of each relation against 1000/T in the Coast-Redfern and Broido relations while in the Horowitz-Metzger relation by plotting against $\theta$ [27-30]. The thermo-kinetic results using the three models of kinetic equations were summarized in Table 5-7. The positive values of $\Delta \mathrm{G}$ refer to nonspontaneous reactions in all decomposition steps of complexes. The change of enthalpy $(\Delta \mathrm{H})$ recorded positive values that refer to the endothermic nature of all the decomposition steps. The increase of activation energy values refers to an increase in thermal stability. On the other hand, the negative values of entropy indicate that decomposition reactions in the complexes occurred at a very low rate [10,24,27]. The correlation coefficient ( $r$ ) and activation energy demonstrated the highest values in the Coast-Redfern method compared with Broido and Horowitz-Metzger methods. The first decomposition step of the lead complex in three kinetic models is shown in Fig. 9. 
Table 7. Thermodynamic parameters using Horowitz-Metzger relation

\begin{tabular}{cllccccc}
\hline Complex & Step & $\begin{array}{c}\mathrm{A} \\
\left(\mathrm{S}^{-1}\right)\end{array}$ & $\begin{array}{c}\mathrm{E} \\
\left(\mathrm{KJ} \mathrm{mol}^{-1}\right)\end{array}$ & $\begin{array}{c}\Delta \mathrm{H} \\
\left(\mathrm{KJ} \mathrm{mol}^{-1}\right)\end{array}$ & $\begin{array}{c}\Delta \mathrm{S} \\
\left(\mathrm{KJ} \mathrm{mol}^{-1} \mathrm{~K}^{-1}\right)\end{array}$ & $\begin{array}{c}\Delta \mathrm{G} \\
\left(\mathrm{KJ} \mathrm{mol}^{-1}\right)\end{array}$ & $\mathrm{r}$ \\
\hline \multirow{2}{*}{$\mathrm{ZPb}$} & $1^{\text {st }}$ & 0.108 & 20.278 & 16.346 & -0.267 & 142.738 & 0.989 \\
& $2^{\text {nd }}$ & 0.282 & 123.820 & 117.850 & -0.262 & 306.478 & 0.968 \\
& $3^{\text {rd }}$ & 0.304 & 171.744 & 164.985 & -0.263 & 378.910 & 0.851 \\
& $4^{\text {th }}$ & 0.115 & 109.154 & 100.358 & -0.273 & 389.574 & 0.884 \\
\hline \multirow{2}{*}{$\mathrm{ZCd}$} & $1^{\text {st }}$ & 0.186 & 21.734 & 18.633 & -0.260 & 115.885 & 0.833 \\
& $2^{\text {nd }}$ & 0.368 & 75.903 & 71.805 & -0.257 & 198.696 & 0.911 \\
& $3^{\text {rd }}$ & 0.257 & 128.611 & 122.226 & -0.264 & 325.033 & 0.987 \\
\hline \multirow{7}{*}{$\mathrm{ZCo}$} & $1^{\text {st }}$ & 0.264 & 26.905 & 24.012 & -0.257 & 113.533 & 0.967 \\
& $2^{\text {nd }}$ & 0.258 & 51.933 & 47.876 & -0.260 & 174.873 & 0.950 \\
& $3^{\text {rd }}$ & 0.197 & 99.724 & 93.298 & -0.266 & 299.155 & 0.964 \\
& $4^{\text {th }}$ & 0.385 & 265.166 & 257.742 & -0.261 & 491.660 & 0.951 \\
& $5^{\text {th }}$ & 0.121 & 154.310 & 144.100 & -0.274 & 480.844 & 0.864 \\
\hline \multirow{2}{*}{$\mathrm{ZNi}$} & $1^{\text {st }}$ & 0.411 & 43.273 & 40.338 & -0.253 & 129.893 & 0.963 \\
& $2^{\text {nd }}$ & 0.505 & 86.286 & 82.561 & -0.253 & 196.340 & 0.962 \\
& $3^{\text {rd }}$ & 0.054 & 12.592 & 8.202 & -0.273 & 152.822 & 0.725 \\
& $4^{\text {th }}$ & 0.281 & 116.329 & 110.526 & -0.262 & 293.766 & 0.866 \\
& $5^{\text {th }}$ & 0.239 & 142.522 & 135.555 & -0.265 & 357.957 & 0.871 \\
\hline
\end{tabular}
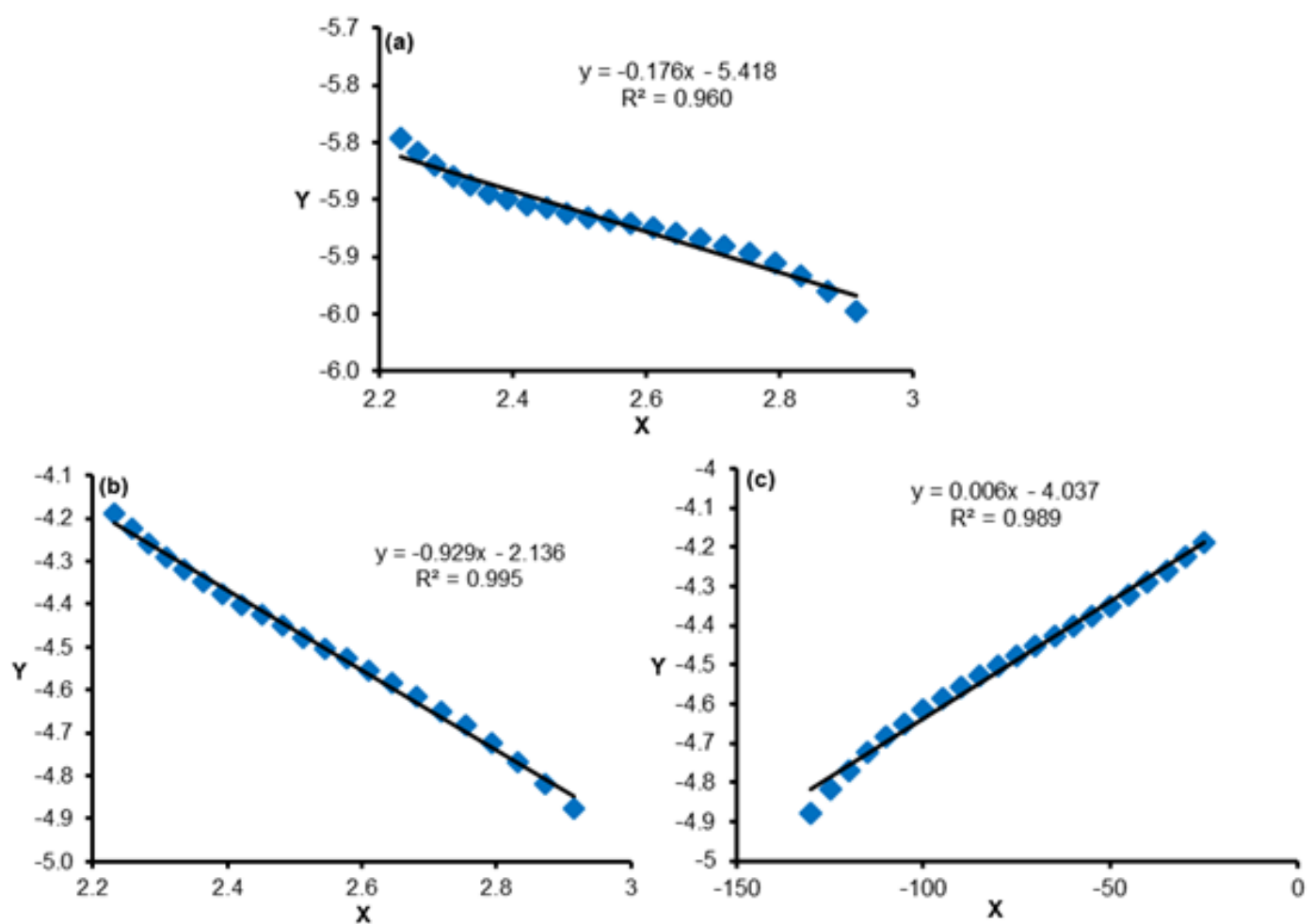

Fig 9. The first decomposition step of lead complex in three kinetic models as (a) Coats-Redfern (b) Broido and (c) Horowitz-Metzger 


\section{- CONCLUSION}

Selenazone ligand was synthesized (by replacing the sulfur atom in the dithizone molecule to the selenium atom), and their complexes were prepared with divalent ions $\left(\mathrm{Pb}^{2+}, \mathrm{Cd}^{2+}, \mathrm{Co}^{2+}\right.$, and $\left.\mathrm{Ni}^{2+}\right)$ in methanolic solution. The results obtained from XRD and SEM measurements indicating the preparation of nanoparticles for selenazone ligand. The thermal study was used to suggest the geometric structure of the complexes. The kineticthermodynamic parameters were computed using three kinetic models (Coast-Redfern, Broido, and HorowitzMetzger). The Coast-Redfern model has better fit and more accurate for computing the kinetic-thermodynamic parameters in all the decomposition steps of the complexes. The nickel complex demonstrated the highest value of activation energy and has more thermal stability when compared with other complexes. The thermal stability of the complexes was in the following order: $\mathrm{ZNi}$ $>\mathrm{ZCo}>\mathrm{ZCd}>\mathrm{ZPb}$.

\section{- ACKNOWLEDGMENTS}

The authors would like to thank the University of Basrah/Faculty of Science and Marine Science Center for supporting, and laboratory facilitates to achieve this work.

\section{- REFERENCES}

[1] Perrone, D., Monteiro, M., and Nunes, J.C., 2015, "Chapter 1 The Chemistry of Selenium" in Selenium: Chemistry, Analysis, Function and Effects, ${ }^{\text {st }}$ Ed., Eds. Preedy, V., The Royal Society of Chemistry, London, UK.

[2] Li, Q., Zhang, Y., Chen, Z., Pan, X., Zhang, Z., Zhu, J., and Zhu, X., 2020, Organoselenium chemistrybased polymer synthesis, Org. Chem. Front., 7 (18), 2815-2841.

[3] Wirth, T., 2012, Organoselenium Chemistry: Synthesis and Reactions, ${ }^{1 s t}$ Ed., Wiley-VCH Verlag $\mathrm{GmbH} \&$ Co. KGaA, Weinheim, Germany.

[4] Ward, V.R., 2012, Aspects of organoselenium chemistry, Dissertation, School of Chemistry and Physics, University of Adelaide.

[5] Achibat, H., AlOmari, N.A., Messina, F., Sancineto, L., Khouili, M., and Santi, C., 2015, Organoselenium compounds as phytochemicals from the Natural Kingdom, Nat. Prod. Commun., 10 (11), 18851892.

[6] Shini, S., Sultan, A., and Bryden, W.L., 2015, Selenium biochemistry and bioavailability: Implications for animal agriculture, Agriculture, 5 (4), 1277-1288.

[7] Coleman, R.A., Kazan, J., and Vega, M.L., 1968, Synthesis of Chromotropic Colorants, Project Reference: 1KO-24401-A113, U.S. Army Materiel Command, U.S. Army Natick Laboratories, Massachusetts.

[8] Ramakrishna, R.S., and Irving, H.M.N.H., 1969, Selenazone: The analogue of dithizone, Anal. Chim. Acta, 48 (2), 251-266.

[9] Shen, H., Zhu, H., Song, M., Tian, Y., Huang, Y., Zheng, H., Cao, R., Lin, J., Bi, Z., and Zhong, W., 2014, A selenosemicarbazone complex with copper efficiently down-regulates the $90-\mathrm{kDa}$ heat shock protein HSP90AA1 and its client proteins in cancer cells, BMC Cancer, 14 (1), 629.

[10] Ebrahimi, H.P., Hadi, J.S., Abdulnabi, Z.A., and Bolandnazar, Z., 2014, Spectroscopic, thermal analysis and DFT computational studies of salentype Schiff base complexes, Spectrochim. Acta, Part A, 117, 485-492.

[11] Abdulsahib, H.T., 2015, Synthesis and characterization of some polymers for the removal of some heavy metal ions and bentonite in wastewaters, Dissertation, University of Basrah, Iraq.

[12] Fresneda, M.A.R., Martín, J.D., Bolívar, J.G., Cantos, M.V.F., Bosch-Estévez, G., Moreno, M.F.M., and Merroun, M.L., 2018, Green synthesis and biotransformation of amorphous Se nanospheres to trigonal 1D Se nanostructures: Impact on Se mobility within the concept of radioactive waste disposal, Environ. Sci.: Nano, 5 (9), 2103-2116.

[13] Shah, C.P., Singh, K.K., Kumar, M., and Bajaj, P.N., 2010, Vinyl monomers-induced synthesis of polyvinyl alcohol-stabilized selenium nanoparticles, Mater. Res. Bull., 45 (1), 56-62. 
[14] Brgaal, K.S., 2020, Adsorption and biochemical study for the removal of dyes from water using modified organic compounds obtained from scrap ground tire rubber, Dissertation, University of Basrah, Iraq.

[15] Juhász, L., Moldován, K., Gurikov, P., Liebner, F., Fábián, I., Kalmár, J., and Cserháti, C., 2021, False morphology of aerogels caused by gold coating for SEM imaging, Polymers, 13 (4), 588.

[16] Bhatia, P., Pandey, S., Prakash, R., and Nagaraja, T.P., 2014, Enhanced anti-oxidant activity as a function of Selenium hyperaccumulation in Agaricus bisporus cultivated on Se-rich Agri-residues, J. Biol. Act. Prod. Nat., 4 (5-6), 354-364.

[17] Karcz, D., Matwijczuk, A., Kamiński, D., Creaven, B., Ciszkowicz, E., Lecka-Szlachta, K., and Starzak, K., 2020, Structural features of 1,3,4-thiadiazole-derived ligands and their $\mathrm{Zn}$ (II) and $\mathrm{Cu}$ (II) complexes which demonstrate synergistic antibacterial effects with Kanamycin, Int. J. Mol. Sci., 21, 5735.

[18] Aly, S.A., and Fathalla, S.K., 2020, Preparation, characterization of some transition metal complexes of hydrazone derivatives and their antibacterial and antioxidant activities, Arabian J. Chem., 13 (2), 37353750 .

[19] Dianu, M.L., Kriza, A.A, Stanica, N., and Musuc, A.M., 2010, Transition metal M(II) complexes with isonicotinic acid 2-(9-anthrylmethylene)-hydrazide, J. Serb. Chem. Soc., 75 (11), 1515-1531.

[20] Ntoi, L.L.A., 2016, Multiple chromisms associated with dithizone, Dissertation, University of the Free State, Bloemfontein, South Africa.

[21] Ahmadi, R.A., Hasanvand, F., Bruno, G., Rudbari, H.A., and Amani, S., 2013, Synthesis, spectroscopy, and magnetic characterization of copper(II) and cobalt(II) complexes with 2-amino-5-bromopyridine as ligand, Int. Scholarly Res. Not., 2013, 426712.

[22] Perera, T., Marzilli, P.A., Fronczek, F.R., and Marzilli, L.G., 2010, NH NMR shifts of new, structurally characterized $f a c-\left[\operatorname{Re}(\mathrm{CO})_{3}(\text { polyamine })\right]^{\mathrm{n}+}$ complexes probed via outer-sphere $\mathrm{H}$-bonding interactions to anions, including the paramagnetic [ReIVBr $\left.]_{6}\right]^{2-}$ anion, Inorg. Chem., 49 (12), 55605572.

[23] Palu, D.S., Paoli, M., Casabianca, H., Casanova, J., and Bighelli, A., 2020, New compounds from the roots of corsican Calicotome villosa (Poir.) Link.: Two pterocarpans and a dihydrobenzofuran, Molecules, 25 (15), 3467.

[24] Hadi, J.S., Abdulnabi, Z.A., and Dhumad, A.M., 2017, Synthesis, spectral characterization, thermal analysis and DFT computational studies of $2-(1 \mathrm{H}-$ indole-3-yl)-5-methyl-1H-benzimidazole and their $\mathrm{Cu}(\mathrm{II}), \mathrm{Zn}(\mathrm{II})$ and $\mathrm{Cd}(\mathrm{II})$ complexes, Eur. J. Chem., 8 (3), 252-257.

[25] Haines, P.J., 1995, Thermal Methods of Analysis, Springer Science, Netherlands.

[26] Hadi, J.S., and Abdul Kareem, A.A., 2020, Thermogravimetric study of some Schiff base metal complexes, Int. J. Appl. Chem., 7 (1), 34-44.

[27] Abdulnabi, Z.A., 2013, Preparation, spectroscopic characterization, thermal study and biological activity of some complexes derived from Schiff base and benzimidazole derived from 4methylphenelendiamine, Thesis, University of Basrah, Iraq.

[28] Gopalakrishnan, S., and Sujatha, R., 2011, Comparative thermoanalytical studies of polyurethanes using Coats-Redfern, Broido and Horowitz-Metzger methods, Chem. Sin., 2 (5), 103117.

[29] Ofem, M.I., Muhammed, M., and Umar, M., 2015, Thermal properties of chitin whiskers reinforced poly(acrylic acid), Int. J. Sci. Technol. Res., 4 (9), 281-288.

[30] Gul, H., Shah, A.H., Gul, S., Arjomandi, J., and Bilal, S., 2018, Study on the thermal decomposition kinetics and calculation of activation energy of degradation of poly(o-toluidine) using thermogravimetric analysis, Iran. J. Chem. Chem. Eng., 37 (1), 193-204. 